\title{
Matizes VERDES, MODERNIZAÇÃO ECOLÓGICA E USURPAÇÃO DA BIODIVERSIDADE
}

\author{
GREEN NUANCES, ECOLOGICAL MODERNIZATION \\ AND BIODIVERSITY MISAPPROPRIATION
}

Filipe Aquino ${ }^{a}$

Resumo A partir da categorização proposta pelo sociólogo espanhol Joan Martínez Alier sobre as correntes ecológicas, este artigo analisa diferentes matizes presentes no movimento ambientalista, buscando apontar e comentar suas múltiplas tendências, considerações e implicações. Ao utilizar a Amazônia como pano de fundo e as transformações lá ocorridas nos últimos vinte anos, investigam-se as condições que situam a modernização ecológica como instrumento da tecnociência que age sob e sobre a biodiversidade a partir da biotecnologia, transformando a questão ambiental em um campo de conflitos, depredação sociocultural e renovação econômica do grande capital transnacional.

Palavras-chave ecologia; ambientalismo; biodiversidade; Amazônia.

\begin{abstract}
Based on the categorization proposed by the Spanish sociologist Joan Martinez Alier on the ecological currents, this article analyzes different nuances present in the environmental movement seeking to identify and comment on its multiple tendencies, considerations and implications. Using the Amazon region and the transformation that have occurred there over the past 20 years as a background, we investigate the conditions that situate ecological modernization as a techno science instrument which act under and upon biodiversity from biotechnology, transforming the environmental issue in a field of conflicts, sociocultural depredation and economic renewal of the large transnational capital.
\end{abstract}

Keywords ecology; environmentalism; biodiversity; Amazon.

a Mestre em Comunicação e Semiótica pela Pontifícia Universidade Católica de São Paulo (PUC-SP). Atualmente, doutorando em Sociologia pela Universidade do Porto. 


\section{INTRODUÇÃO: INSUSTENTABILIDADES}

O conceito de responsabilidade socioambiental deriva diretamente da ideia de crescimento econômico e surge como forma de enfrentar discursivamente a insustentabilidade do atual modelo político, social, econômico e ambiental. "A teoria do desenvolvimento sustentável possui raízes nas discussões sobre ambientalismo que buscavam um conceito alternativo de desenvolvimento a partir dos debates sobre os riscos da degradação do meio ambiente" (SouzA, 1995, p. 5). Sob esse ponto de vista, o desenvolvimento sustentável desponta como uma "nova filosofia do desenvolvimento que combina eficiência econômica, com justiça social e prudência ecológica" (BRÜZEKE, 1994, p.b9). Compreender as motivações e a racionalidade dos diferentes atores é indispensável para que se entenda a nova estratégica discursiva que utiliza o discurso socioambiental como força-motriz do ideal de desenvolvimento hegemônico atualmente vigente. Sob a ótica da sustentabilidade, investiga-se, ainda, a discriminação social, econômica e ambiental das populações periféricas, fruto do ciclo danoso do grande capital.

Para situar mais claramente essas questões, partiu-se de análises do movimento ambientalista, ou movimento verde, que se apresenta como amplo, com variadas formas de pensar e agir.

Sob a chancela do movimento ecológico, veremos o desenvolvimento das lutas em torno de questões as mais diversas: extinção de espécies, desmatamento, uso de agrotóxicos, urbanização desenfreada, explosão demográfica, poluição do ar e da água, contaminação de alimentos, erosão dos solos, diminuição das terras agricultáveis pela construção de grandes barragens, ameaça nuclear, guerra bacteriológica, corrida armamentista, tecnologias que afirmam a concentração de poder, entre outras. Não há, praticamente, setor do agir humano onde ocorram lutas e reivindicações que o movimento ecológico não seja capaz de incorporar (GonÇAlVEs, 2006, p. 12).

Ante a multiplicidade de enfoques e abordagens da questão verde, optou-se pelo mapeamento proposto pelo sociólogo Joan Martínez Alier (2009), que divide as correntes do ambientalismo em três grandes grupos, com diferentes práticas socioteóricas: o culto ao silvestre, o evangelho da eficiência e o ecologismo dos pobres. 


\section{O CULTO AO SILVESTRE}

O culto ao silvestre ou culto à vida selvagem é a corrente do movimento ambientalista que difunde a ideia de defesa da natureza intocada, semeando o amor aos bosques e aos cursos d'água. O movimento ambientalista que prega o culto à vida silvestre centra a resolução dos problemas ecológicos na preservação (pura e simples) da natureza idílica, natural, intocada. Para Joan Martínez Alier (2009, p. 22):

O "culto ao silvestre" surge do amor às belas paisagens e de valores profundos, jamais para os interesses materiais. A biologia da conservação, que se desenvolve desde 1960, fornece a base científica que respalda essa primeira corrente ambientalista.

O culto ao silvestre ganhou espaço na mídia especialmente por denunciar que a "perda da biodiversidade caminha de forma rápida" (MarTínez Alier, 2009, p. 23), com o desaparecimento de espécies animais e vegetais que antes eram abundantes. A agricultura, de subsistência ou do agronegócio, desagrada profundamente os defensores dessa corrente ecológica, uma vez que "essas atividades ganharam espaço às expensas da vida silvestre” (MARTínez Alier, 2009, p. 24). A sacralidade da natureza, portanto, é o ideal-base, sendo o homem apenas mais um elemento a compor o universo. Carlos Cardoso Aveline (2007, p. 14) define assim os ideais da ecologia profunda (um outro significante para o culto ao silvestre):

A natureza, cuja evolução é eterna, possui valor em si mesma, independentemente da utilidade econômica que tem para o ser humano que vive nela. Esta ideia central define a chamada ecologia profunda - cuja influência é hoje cada vez maior - e expressa a percepção prática de que o homem é parte inseparável, física, psicológica e espiritualmente, do ambiente em que vive.

Em resumo: a corrente ecológica denominada culto ao silvestre apresenta como principal proposta política a manutenção de "reservas naturais, em geral denominadas parques nacionais ou naturais, livres da ação e interferências humanas" (MarTínez Alier, 2009, p. 24). Além disso, os componentes dessa corrente do ecologismo orientam-se para a preservação da vida silvestre, "sem se pronunciar diretamente sobre a industrialização ou a urbanização, mantendo-se indiferentes ou em oposição ao crescimento econômico, muito preocupados com 
o crescimento populacional e respaldados cientificamente pela biologia conservacionista” (MARTínez Alier, 2009, p. 38).

\section{O EVANGELHO DA ECOEFICIÊNCIA}

O ano de 1972 singularizou-se na história do pensamento ambientalista, pois foi quando surgiu um estudo de fundamental relevância para as questões relacionadas ao meio ambiente. Para Anthony Giddens (2010, p. 86), o estudo, que ficou conhecido como Limites do crescimento, do Clube de Roma ${ }^{1}$, afirmou que "nossa civilização está esgotando os recursos dos quais depende a continuação de nossa existência”. Foi também no ano de 1972 que a Conferência das Nações Unidas para o Meio Ambiente Humano destacou a importância de conciliar o desenvolvimento econômico com o uso sustentável dos recursos naturais. Com o pensamento da valorização do meio ambiente, em especial dos recursos naturais nele disponíveis, a corrente ecológica denominada evangelho da ecoeficiência é o segmento do pensamento ambientalista que se "preocupa com o manejo sustentável e com o 'uso responsável' dos recursos naturais" (MARTínez Alier, 2009, p. 27). Preocupa-se também com o controle dos níveis de contaminação do ar, da água e dos solos. O foco dos entusiastas dessa corrente está direcionado aos impactos ambientais da produção de bens e aos riscos à saúde decorrentes de atividades industriais, da urbanização e da agricultura e pesca modernas.

As novas tecnologias e a internalização das externalidades ${ }^{2}$ se apresentam como fundamentais para a modernização tecnológica e para a economia ecológica como um todo. Os defensores do evangelho da ecoeficiência advogam pelo crescimento econômico, porém apregoam a tal crescimento a ideia de "desenvolvimento sustentável”. É aqui que reside o pensamento mais visível nos media e na sociedade contemporânea, seja por parte das empresas, seja da parte dos cidadãos, seja por parte do poder público: a ideia de aproveitar melhor os recursos e as matérias-primas e ter uma vida "sustentável". Uma dita vida sustentável atrela-se

1 Criado em 1968, é formado por "personalidades” de diferentes comunidades, como acadêmica, política, empresarial, religiosa, entre outras. Discutem-se especialmente temas como energia, poluição, saneamento, saúde, ambiente, tecnologia e crescimento populacional.

2 Uma externalidade acontece quando uma pessoa ou um processo produtivo influencia o bem-estar de outra pessoa. A externalidade pode ser positiva - quando gera, por exemplo, empregos para a população ao redor - ou negativa - quando destrói recursos naturais. O processo de internalização das externalidades deve ser a base de toda a política ambiental, pois assim criam-se formas para que a empresa seja obrigada a investir em controles ambientais que mitiguem os impactos de seus processos, além de fazer com que os custos socioambientais da poluição sejam integrados ao processo produtivo por meio de multas ambientais e taxas, por exemplo. 
a um "desenvolvimento responsável" da economia e da sociedade. Para Martínez Alier (2009, p. 28), "efetivamente, a 'ecoeficiência' tem sido descrita como 'o vínculo empresarial com o 'desenvolvimento sustentável”. A palavra desenvolvimento, portanto, demanda alterações na estrutura econômica e social, ao passo que a palavra crescimento significa uma expansão na escala da economia que provavelmente não tem condições de se sustentar ecologicamente. Martínez Alier entende "desenvolvimento" como um termo de forte conotação de crescimento econômico e modernização uniforme. Nessa ordem, para ele seria preferível falar em "sustentabilidade". Giddens (2010, p. 88) alerta: "Os dois termos fundamentais, 'sustentabilidade' e ‘desenvolvimento', têm significados meio contraditórios. 'Sustentabilidade' implica continuidade e equilíbrio, enquanto 'desenvolvimento' implica dinamismo e mudança”. Logo, por mais distintos que possam ser os conceitos sobre sustentabilidade/responsabilidade socioambiental, há um distanciamento entre a prática diária dos chefes governamentais e empresariais e o ideal almejado pelo discurso sustentável, especialmente porque existe uma

inversão de valores, tendo em conta que o discurso da lucratividade a partir da sustentabilidade indica que o mundo ideal sob os aspectos fundamentais do desenvolvimento ainda está sendo sobreposto ou subjugado pela lógica do capital (DA SILVA, 2011, p. 25).

A noção de tempo que norteia o processo, portanto, é a do capital, não a da natureza. É o tempo da concorrência, o da exploração dos recursos naturais, o da necessidade de exportação de toneladas crescentes de recursos minerais, etc. Sob esse parâmetro, há um nítido choque entre o conceito e a ação propostos pelo evangelho da ecoeficiência, que surge como uma nova roupagem para que o capitalismo continue hegemônico e vencedor.

Desenvolvimento sustentável apresenta uma conotação positiva de que é possível aliar crescimento econômico, uso adequado dos recursos da natureza e melhoria da qualidade de vida. Não fica claro, entretanto, de que forma essa interrelação pode ser conseguida na prática, sem profundas transformações, tanto a nível local quanto a nível mundial, nas relações de poder que se estabeleceram historicamente a partir da gênese e desenvolvimento do modo de produção capitalista (SouzA, 1995, p. 37). 
Quando se trata da questão ecoeficiente, é comum encontrar um aglomerado de metas e objetivos como conceitos. Exemplificando a dificuldade em encontrar uma fórmula precisa para se obter a ecoeficiência, William Lafferty e James Meadowcroft destacam:

\begin{abstract}
Desenvolvimento sustentável indica uma preocupação interdependente com: a promoção do bem-estar humano; a satisfação das necessidades básicas; a proteção do meio ambiente; a consideração para com o destino das futuras gerações; a conquista da igualdade entre ricos e pobres; e a participação numa base ampla no processo decisório (apud GIDDENS, 2010, p. 88).
\end{abstract}

Desse modo, em sentido mais simples, pode-se afirmar que a sustentabilidade implica que, ao lidar com problemas ambientais, está-se "em busca de soluções duradouras, não de jeitinhos a curto prazo” (GidDEns, 2010, p. 88). Por conta disso, é interessante acompanhar o processo de aceitação do conceito de sustentabilidade nas empresas, sobretudo para delimitar o ponto a partir do qual ele foi transformado em arma discursiva empresarial fundamental para a construção de imagem de marca ecorresponsável. Em 1989, na Suécia, Karl-Henrik Robèrt desenvolveu parâmetros para o melhor aproveitamento de insumos e recursos denominados The Natural Step (TNS). Apesar de o problema ecológico gerar discussões há anos, especialmente na Europa, até a data, o tema não era tão corriqueiro na agenda das corporações. "Treze anos atrás, quando o TNS iniciou as suas atividades, a percepção de que as empresas eram totalmente ignorantes do ponto de vista ambiental era maior do que hoje" (RoBÈrT, 2011, p. 15).

Atualmente, a agenda midiática dá voz - e, em outros casos, "vende espaços" - a empresas engajadas em relação aos temas ambientais e - na pior das hipóteses - cada vez mais empenhadas em comunicar suas práticas de sustentabilidade. $\mathrm{O}$ Ikea e o McDonald's suecos - dois casos citados por Karl-Henrike Robèrt - servem de exemplos. No Ikea, um dos problemas enfrentados pela organização era que "as pessoas haviam rotulado o desenvolvimento sustentável de 'frescura" (RoBÈrT, 2011, p. 98). Para combater esse pensamento, o Ikea criou um folheto intitulado "Lixo é dinheiro", no qual argumentou que o desperdício equivaleria a custos, pois revelava que algo não estava operando de forma totalmente correta. O McDonald's sueco, por sua vez, sofreu com a administração municipal, que resolveu processar a companhia por não usar embalagens reutilizáveis: o lixo produzido não era compatível com as resoluções da Agenda 21. A empresa acabou por realizar um acordo com o poder público municipal e se comprometeu a "adotar energia renovável, fazer 
suas compras de alimentos com fornecedores agrícolas que possuíssem programas administrativos voltados para o desenvolvimento sustentável, além de desenvolver programas de reciclagem em todos os seus restaurantes” (RовÈRT, 2011, p. 136).

Sob esse quadro, na perspectiva de aproveitar tudo o que for possível para reduzir o desperdício, os praticantes do evangelho da ecoeficiência acabam por utilizá-lo como uma forma de ganho, tanto em termos de redução de despesas quanto em termos de construção de "imagem corporativa", pois, como alerta Laymert Garcia dos Santos (2011, p. 30): “o lema do capitalismo verde é salvar o planeta e ganhar dinheiro ao mesmo tempo".

\section{O ECOLOGISMO DOS POBRES}

O ecologismo dos pobres, ecologismo popular ou movimento por justiça ambiental centra seus esforços na diminuição dos conflitos originados a partir dos embates ambientais em níveis local, regional, nacional e global, que são causados pelo crescimento econômico e pela desigualdade social. É também denominada ecologismo de livehood (subsistência ou ganha-pão), do sustento e da sobrevivência humana (GARI, 2000 apud MARTínez Alier, 2009) e ecologia da libertação (PEET; WATts, 1996, apud MARTínez Alier, 2009). Essa corrente do ambientalismo ressalta que o crescimento econômico implica maiores impactos no meio ambiente, dando destaque para a alteração no deslocamento geográfico das fontes de recursos e das áreas de descarte dos resíduos operacionais. Nesse sentido, de acordo com Martínez Alier (2009, p. 34), observa que

países industrializados dependem de importações provenientes do Sul para atender parcela crescente das suas demandas por matérias-primas e bens de consumo. Os Estados Unidos importam metade do petróleo que consomem. A União Européia importa uma quantidade de materiais (inclusive energéticos) quase quatro vezes maior do que a que exporta.

O eixo principal dessa corrente ecológica não é uma reverência à natureza, mas sim um interesse material pelo meio ambiente como fonte de condição para a subsistência; não é advogar em razão dos direitos de espécies ameaçadas de extinção e da preocupação com as futuras gerações de humanos, mas sim, pelos humanos pobres de hoje (MARTínEz AliER, 2009). Portanto, o ecologismo dos pobres não compartilha dos mesmos fundamentos éticos nem estéticos das correntes anteriores citadas. Sua preocupação tem origem em uma demanda por justiça 
social contemporânea, em particular se entender-se que as fronteiras do gás, do petróleo, do alumínio, do cobre, do eucalipto, do ouro, da soja (transgênica ou não), etc. avançam na direção de novos territórios, e, a partir disso, deve-se pensar na geração de impactos que não são solucionados pelas políticas econômicas ou pelas inovações tecnológicas. Em geral, esses impactos atingem de forma desproporcional diferentes grupos sociais. Na medida em que a escala da economia é expandida, mais resíduos são gerados e mais os sistemas naturais são comprometidos, o que acaba deteriorando os direitos das gerações futuras. Alguns exemplos de conflitos ambientais nos quais o ecologismo dos pobres deve ser considerado são os provocados pelo uso da água, pelo acesso às florestas, contaminação de áreas e o comércio ecológico desigual. Em muitos contextos, os agentes participantes de ambos os lados desses conflitos não utilizavam um discurso ambientalista - isso explica por que o ecologismo dos pobres e o movimento por justiça ambiental não foram plenamente identificados até os anos de 1980. O fato é que a continuidade do atual sistema de produção do capitalismo hegemônico é ambientalmente insustentável e socialmente injusto, o que acaba por intensificar os conflitos socioambientais de diversas regiões. Para enfrentar esses problemas, o ecologismo dos pobres tem como fundamentos a economia ecológica e a ecologia política.

A economia ecológica tem como seu precursor mais importante o economista Georgescu-Roegen, cujos estudos entre os anos cinquenta e setenta buscaram integrar os processos econômicos e os processos de organização da natureza em seus fluxos de energia e materiais na produção da vida, em especial através das implicações das leis da termodinâmica no funcionamento da economia. [...] Uma das principais contribuições de Georgescu-Roegen e diversos de seus seguidores tem sido a crítica do regime energético da atual sociedade industrial e de mercado, baseado no uso intensivo de combustíveis fósseis não renováveis que aceleram processos entrópicos globais no planeta. As características desse regime energético, aliado aos padrões de produção e consumo das sociedades capitalistas contemporâneas, geram intensos fluxos de materiais e energia incompatíveis com o metabolismo ecológico e social do planeta, sendo, portanto, insustentáveis. A consequência é a aceleração de entropias globais, ou seja, processos de desorganização dos ecossistemas e da própria vida, acentuados pela emergência dos chamados riscos ecológicos globais nas últimas décadas, como as mudanças climáticas globais (PorTo; Milanez, 2009, p. 1985).

A ecologia política, por sua vez, apresenta-se como um 
campo de discussões teóricas e políticas que estuda os conflitos ecológicos distributivos, ou simplesmente os conflitos sócio-ambientais. Ela se fortalece principalmente a partir dos anos 80 pela crescente articulação entre os movimentos ambientalistas e sociais. A ecologia política amplia a crítica dos fundamentos filosóficos da economia neoclássica ao avançar sobre a economia prática de tradição marxista, incorporando questões ecológicas no entendimento das dinâmicas econômicas e de poder que caracterizam as sociedades modernas (MARTíNEZ Alier; PORTO, 2007, p. 508).

Portanto, a articulação entre ecologia política e economia ecológica fornece uma importante base teórica porque se passa a considerar os problemas socioambientais como conflitos distributivos, frutos das desigualdades e contradições dos processos econômicos e sociais atuais. Desafortunadamente, esses conflitos concentram-se sobre as populações mais pobres, discriminadas e socialmente excluídas. Citam-se como conflitos desiguais as lutas empreendidas pelo movimento Chipko em defesa das floretas no Himalaia; a união preservacionista liderada por Chico Mendes; a resistência dos atingidos por barragens espalhados por diversas regiões do Brasil; a disputa por vez e voz dos pescadores artesanais residentes nas imediações do Porto do Itaqui, em São Luís, capital do Maranhão; o sofrimento das dezenas de famílias que vivem ao longo da Estrada de Ferro Carajás, no Norte do país; a luta empreendida pelas populações indígenas e quilombolas pelo reconhecimento de suas histórias e seus territórios; entre muitos outros casos. "Tais conflitos, porém, tendem a se radicalizar em situações de injustiça presentes em sociedades marcadas por fortes desigualdades sociais, discriminações étnicas e assimetrias de informação e poder" (PorTo; Milanez, 2009, p. 1985).

Nessa perspectiva, os processos de desenvolvimento que formam "centros" e "periferias" regionais e mundiais precisam ser questionados, pois não há como falar em sustentabilidade enquanto o meio ambiente é ameaçado pelo crescimento populacional, pelo abandonado dos povos da floresta e das periferias, pela crescente exploração dos recursos minerais e pelo hiperconsumo.

\section{A AMAZÔNIA COMO ÚLTIMA FRONTEIRA: RIQUEZAS MUNDIALMENTE RECONHECIDAS E AMEAÇADAS}

Percebe-se que há um enfrentamento entre os agentes da expansão econômica e os da conservação do meio ambiente. A principal proposta para a solução desse enfrentamento parece residir na modernização ecológica - ao menos para aqueles que ainda acreditam nas promessas de inclusão do desenvolvimento tecnocientí- 
fico. Para Laymert Garcia dos Santos (2011), essas promessas se esfumaçaram e parecem só fazer sentido a partir do insistente assédio da mídia e, em especial, da publicidade. A ideia de modernização ecológica caminha sob dois pontos principais: o primeiro, de ordem econômica, opera, de forma geral, a partir de ecoimpostos e mercados de licenças de emissões; o segundo, com base na ordem tecnológica, atua no apoio de medidas voltadas para a economia e/ou melhor aproveitamento da energia e de matérias-primas - encaixando-se perfeitamente ao evangelho da ecoeficiência outrora citado.

Alguns estudiosos, políticos, ambientalistas e, principalmente, corporações transnacionais apostam que as novas tecnologias resolverão os problemas surgidos na difícil relação economia-meio ambiente. Entretanto, deve-se ressaltar que as novas tecnologias não são, necessariamente, a "solução perfeita", principalmente se considerar-se a existência de perigos ${ }^{3}$ (novos e antigos, alguns ainda não totalmente conhecidos), como a localização de incineradores, o uso de áreas de destinação e de armazenagem de resíduos radioativos, o uso das sementes transgênicas, geneticamente modificadas, ou ainda a questão dos transportes e novos combustíveis, como o etanol $^{4}$, entre outros exemplos. "Até pouco tempo atrás, tratar de uma possível crise ambiental no Brasil era algo marginal, pois tal fato era considerado um fenômeno de país industrializado" (SANTos, 2011, p. 35). Hoje, sobretudo pela riqueza da biodiversidade amazônica, pela quantidade de minerais encontrada em solo nacional e pelas necessidades e opressões socioeconômicas que o mundo globalizado impõe, em especial a determinadas populações, é premente tratar, no Brasil, da relação entre economia e meio ambiente. Não há mais como negar que a questão ambiental seja uma questão maior.

Muitos países criaram, inspirados por doutrinas liberais, projetos nacionais de "construção". No Brasil, sob a rubrica do "desenvolvimento", esses ideais cresceram com o amparo do Estado e tomaram a forma de uma aliança entre diferentes setores da elite e das classes médias urbanas (Rocha, 2010). Nesse espectro, "a Amazônia

3 Conforme destaca Laymert Garcia dos Santos (2007, p. 52), o risco, o acidente e o efeito colateral são partes inerentes do progresso tecnológico. A tecnociência parece só saber lidar com os riscos tecnológicos propondo mais tecnologia, o que faz o risco mudar de patamar. "Nesse sentido, e paradoxalmente, quanto mais avança o progresso, mais avançam o risco e a incerteza".

4 Segundo notícia veiculada em 09/11/2008 pelo jornal O Estado de São Paulo, a União da Indústria de Cana-de-Açúcar (UNICA) efetuou estudos e concluiu que, ao longo dos primeiros cinco anos de uso da tecnologia flex fuel, o Brasil "economizou" 42,5 milhões de toneladas de dióxido de carbono (CO2), que deixaram de ser emitidas graças à substituição de gasolina por álcool combustível. Segundo o estudo, isso equivale a três anos e meio de emissões de $\mathrm{CO} 2$ da cidade de São Paulo, ou seja, é como se todos os veículos e fábricas da metrópole tivessem deixado de funcionar durante esse período. Entretanto, o estudo dá a dimensão de que só as novas tecnologias não resolverão todos os problemas: um mês de desmatamento na Amazônia emite tanto $\mathrm{CO} 2$ quanto o que foi economizado com cinco anos de carroflex. 
brasileira foi concebida, pelas elites nacionais, como uma fronteira de recursos na qual o capital poderia refazer seu ciclo de acumulação com base nos novos estoques disponíveis" (CASTRO, 2005, p. 10). Assim, a partir dos anos 1970, a Amazônia brasileira foi integrada ao processo de desenvolvimento nacional. De acordo com Laymert Garcia dos Santos, esse processo consistiu em ocupar e movimentar a Amazônia com grandes projetos agropecuários, rodoviários, hidrelétricos, de mineração e de colonização. Infelizmente, tais projetos têm forte impacto ambiental porque se fundamentaram - e se baseiam, ainda - na destruição ou na facilitação da destruição da floresta. Sintomático da gravidade e da destruição perpetrada com o incentivo do governo brasileiro é o fato de que, "até o final dos anos 80, o Estado brasileiro concedeu US $\$ 2,5$ bilhões em subsídios para os fazendeiros que queriam queimar as florestas para 'beneficiar' a terra, transformando o solo em ‘fazenda aberta”' (SANTos, 2011, p. 22).

A Amazônia brasileira ${ }^{5}$, para efeitos de governo e economia, é delimitada por uma área denominada Amazônia Legal, definida a partir da criação da Superintendência do Desenvolvimento da Amazônia (SUDAM), em 1966. "A chamada Amazônia Legal brasileira tem uma superfície de aproximadamente cinco milhões de $\mathrm{km}^{2}$, ou seja, 60\% do território do Brasil" (SANTos, 2011, p. 17). As florestas úmidas que a compõem caracterizam-se pela vasta biodiversidade animal e vegetal. Para se ter noção dessa riqueza, Laymert Garcia dos Santos (2011, p. 17) destaca: "enquanto na floresta amazônica se conhecem mais de 2.500 espécies de árvores, nas florestas temperadas de toda a França apenas cerca de 50 espécies são encontradas”. Toda essa vastidão permite vislumbrar a riqueza de uma biodiversidade internacionalmente reconhecida e, ao mesmo tempo, ameaçada. O Brasil, país de dimensões continentais, não apresenta, historicamente, um nível de devastação equânime entre as regiões geográficas do país. A floresta amazônica, por exemplo,

permaneceu praticamente intocada até a década de 1960, apesar do ciclo da borracha, que, entre 1840 e 1910, acarretou a drástica redução dos povos indígenas e levou entre 600 mil e 700 mil nordestinos para a região como mão de obra quase escrava (SANTOS, 2011, p. 39-40).

O quadro, a partir dos incentivos desenvolvimentistas da década de 1970, apresenta-se nitidamente diferente. Segundo Philip Fearnside (1991 apud SANTos,

5 "Brasileira" na medida em que a Amazônia é uma floresta tropical que se faz presente em outros sete países (Peru, Colômbia, Venezuela, Equador, Bolívia, Guiana e Suriname). 
2011), as taxas de desmatamento da Amazônia brasileira atingiram em média 22

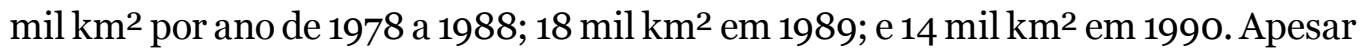
de existir quem pense que ainda há muita área de floresta, é inegável a constatação do poder destrutivo e a quantidade de $\mathrm{km}^{2}$ que foi catapultada à devastação. Para ilustrar com um dado mais atual acerca da devastação histórica ocorrida na área, de acordo com o Ministério do Meio Ambiente (AlEnCASTRO, 2011), a taxa de desmate anual para o ano de 2009-2010 ficou em $7.000 \mathrm{~km}^{2}$. Como lembra Laymert Garcia dos Santos (2011, p. 39):

o processo de ocupação do Brasil fez prevalecer a devastação, e mais de cinco séculos de relação predatória com os recursos naturais consolidaram esse padrão, que acabou acentuado e intensificado pela modernização capitalista e as técnicas industriais do século XX.

Diante de tal situação, é possível afirmar que a Amazônia Brasileira só despertou a atenção do mundo porque seu desmatamento parece conectar, em um cenário catastrófico, três grandes tendências contemporâneas que podem desaguar em um desastre ambiental de proporções globais e desdobramentos inimagináveis: o efeito estufa, a destruição da camada de ozônio e a perda da biodiversidade (SANTos, 2011, p. 15). Essas tendências foram cortejadas ao longo das últimas décadas pela modificação contínua e acelerada da floresta amazônica, ocasionando perdas de coberturas vegetais consideráveis.

Estados como Maranhão, Mato Grosso, Pará e Rondônia tiveram seu uso do solo enormemente alterado, com redução de biodiversidade (florestal e animal) e de técnicas de cultivos agroflorestais desenvolvidas por diversos grupos sociais em unidades produtivas familiares (CASTRO, 2005, p. 6).

A expansão do desmatamento pelo território brasileiro reflete os múltiplos papéis exercidos por diferentes agentes e seus variados objetivos. O poder público, as empresas nacionais e as transnacionais são quem mais se destaca na promoção da degradação, estimulando, assim, o agravamento dos problemas socioambientais.

As causas do desmatamento na Amazônia são múltiplas e traduzem a complexidade dos atores sociais e dos interesses que fazem da fronteira um lugar de encontro, de oportunidades, de capitalização e, justamente por isso, também de tensão e conflito (CASTRO, 2005, p. 6). 
A abertura de estradas, a expansão da infraestrutura (especialmente ferrovias e portos), a exploração desenfreada dos recursos naturais, a derrubada da cobertura florestal, o abuso no uso de energias não renováveis e o avanço da pecuária, da soja e do eucalipto são alguns dos fatores que aceleram o processo de depredação dos ecossistemas. Um dos principais problemas dessa degradação é que ela afeta com diferentes intensidades diferentes grupos sociais, conforme apontado por Martinez Alier em seu conceito de ecologismo dos pobres. Para Laymert Garcia dos Santos (2011, p. 46):

Os povos da floresta podem acabar tendo de enfrentar uma escolha impossível entre o velho, violento e predatório estilo de desenvolvimento que a elite brasileira sempre lhes reservou, ou o desenvolvimento predatório pós-moderno, high-tech, que as corporações transnacionais, o Banco Mundial e as agências internacionais estão planejando para integrar a biodiversidade no mercado global.

Apesar de merecerem toda a atenção por sua situação de vulnerabilidade ante os poderosos interesses dos agentes econômicos, principalmente os transnacionais, os povos da floresta ${ }^{6}$ são apenas parte dos atingidos. O esforço em inserir a Amazônia na lógica do capital acaba por prejudicar toda a sociedade, pois se fundamenta na utilização do patrimônio natural, bem comum de todos nós, como matéria-prima para a feitura de produtos. A realidade econômica a que se está submetido transforma constantemente o mundo e é a grande responsável pela maior parte da perda da biodiversidade. Nos últimos anos, a riqueza da biodiversidade brasileira vem sendo destruída para promover a integração da região amazônica na economia de mercado.

Entretanto, realça-se que a biotecnologia e as revoluções causadas pelas novas técnicas envolvidas nesse processo se configuram como um novo paradigma tecnológico. Porém, nessa conjuntura, um problema ascende: para Laymert Garcia dos Santos (2011, p. 24), "a biotecnologia parece expressar um novo tipo de predação, uma forma bastante perversa de destruição, e uma maneira sofisticada de submeter a biodiversidade à lei do mercado”. Ao contrário do que se pode imaginar, a

6 Laymert Garcia dos Santos (2007, p. 49), relacionando aspectos do desenvolvimento econômico e da sociobiodiversidade, pondera: "Há uma questão que nunca ou quase nunca entra no espectro dos cientistas brasileiros: é a presença em nosso espaço territorial de cerca de duzentos povos indígenas, em sua maior parte concentrados nas terras mais ricas em diversidade biológica, e representando cerca de 10\% da Amazônia Legal. Pois tudo se passa como se eles simplesmente não existissem, não contribuíssem em nada para a singularidade da natureza e da cultura do país, e não significassem nada para o nosso futuro científico". 
biotecnologia não tece loas à biodiversidade, pois, mesmo considerando que a existência da biotecnologia tende, sob uma primeira análise, a minimizar o perigo da extinção, pois, em última instância, manteria o habitat preservado, é possível que a biotecnologia, ao romper com os processos de desenvolvimento natural, ou seja, ao desrespeitar o "tempo da natureza”, acabe por acelerar mudanças genéticas, intervindo diretamente nos genomas, o que, por fim, resultaria em perda da sociobiodiversidade.

O interesse dos agentes do capitalismo pela biodiversidade, em especial por meio da biotecnologia, dá-se diante do fato de que, embora seja difícil, senão impossível, avaliar a riqueza da biodiversidade brasileira em sua totalidade, e até mesmo a riqueza de cada espécie, é possível pulverizá-la em fragmentos microscópicos e apropriar-se dessas unidades mínimas, registrá-las (patenteá-las) e conferir-lhes valor econômico que pode render elevadas quantias no mercado global (SANTos, 2011, p. 25). Exemplo disso é mostrado por Norman Myers (apud SANTos, 2011), ao advertir que um em cada quatro produtos vendidos nas farmácias - seja medicinal, seja farmacêutico - é fabricado a partir de coletas materiais extraídas de plantas nativas das florestas tropicais. Constam nessa lista antibióticos, antivirais, analgésicos, tranquilizantes, diuréticos, entre outros. Em termos de vendas, esses produtos atingem atualmente cerca de U\$ 20 bilhões/ano. A organização não governamental World Resources Institute (WRI), dedicada à causa ambiental, oferece uma dimensão do que está por vir em um de seus relatórios, ao concluir que menos de $1 \%$ das plantas tropicais tiveram seus usos potenciais investigados. Nesse quadro, o potencial da biodiversidade é visto sobretudo como matéria-prima fundamental para a feitura de produtos (alimentos, medicamentos, fibras, etc.) que só a biotecnologia poderá realizar.

Como já visto que a biotecnologia pode se tornar uma ameaça à biodiversidade, fica o questionamento: como esperar que uma força produtora de uniformidade (no caso, a biotecnologia) conserve a diversidade? Partindo do princípio de que o objetivo maior da produção moderna é obter o máximo de produtividade, o que resultaria da produção que envolvesse a riqueza de diversidade pluralista de plantas e animais, o que seria nada mais que uma teia de uniformidade e monocultura. Isso explica, por exemplo, o fato de que muitas florestas, não só na Amazônia, mas em outras regiões, cederam lugar a plantações de soja, arroz ou eucalipto - em geral, a escolha prioriza o que é mais rentável no momento.

A tendência principal permanece, que é a do desflorestamento, da conversão da floresta em pastagens, em áreas degradadas; mais recentemente, as pastagens 
e áreas de sistemas agroflorestais têm sido substituídas pela monocultura de grãos, com a entrada sobretudo da soja (CASTRO, 2005, p. 6).

Com a biotecnologia, instaura-se a conversão de formas de vida em matérias-primas valiosíssimas. A rentabilidade da biotecnologia vem da exploração da biodiversidade por meio do sistema de patentes e do direito de propriedade intelectual (SANTOS, 2011, p. 30). Prova de que a vida pode ser monopolizada é a questão do germoplasma ${ }^{7}$ silvestre, que rendeu US $\$ 66$ bilhões para a economia norte-americana. O patenteamento de diferentes formas de vida ganhou importância quando do debate acerca do futuro da biodiversidade das florestas tropicais. Até 1980, o patenteamento de seres vivos era impossível, até que Ananda Chakrabarty pleiteia junto à Suprema Corte norte-americana os direitos sobre uma bactéria capaz de digerir petróleo que ela mesma criara por meio da reengenharia genética. Diante da proibição do patenteamento de seres vivos, o argumento de Ananda era que sua bactéria não era produto da natureza, e sim um produto manufaturado. A Suprema Corte concedeu ganho de causa, e, a partir desse "ponto conquistado", os agentes do grande capital, em especial os laboratórios das grandes companhias, passaram a se dedicar ainda mais às pesquisas. Em 1985, a primeira planta foi patenteada. Em 1987, o primeiro animal. Em 1992, a Plant Generic Systems registrou uma linhagem especial de vegetais comestíveis resistentes a um herbicida específico ${ }^{8}$.

O patenteamento de algo considerado "humano" resistiu até o caso Moore. Episódio especial na história da leucemia mundial, John Moore, ao enfrentar um tratamento de câncer entre 1976 e 1983, no UCLA Medical Center, despertou o interesse dos médicos acerca das potencialidades de seu corpo, que poderiam render milhões ${ }^{9}$. Em um trabalho conjunto, uma equipe médica dividiu entre si sangue, esperma, medula, pele e tecidos. Em seguida, patenteou partes do corpo do paciente sem seu consentimento ou comunicação, usufruindo de vantagens pecuniárias. Quando Moore descobriu que estava sendo "usado", moveu um processo reivindicando o direito a suas células (SANTOS, 2011). A Suprema Corte norte-americana lhe negou o ganho de causa, argumentando que Moore não detinha direitos de propriedade sobre suas células descartadas, tampouco sobre os lucros obtidos a

7 Germoplasmas são unidades conservadoras de material genético e podem servir para o uso imediato ou como material potencial para uso futuro. São usados especialmente em pesquisas que tratam do "melhoramento genético" de plantas e animais.

8 A Hoeschst, gigante do setor químico, possui os direitos de uso e comercialização sobre a planta e o herbicida.

9 Segundo Laymert Garcia dos Santos, cerca de US\$ 3 bilhões, em valores de 1990. 
partir delas, uma vez que, depois de coletadas, elas deixavam de ser propriedade dele. Após o caso, Marie-Angèle Hermitte, especialista em patentes, sentenciou:

Durante muito tempo o lixo hospitalar não teve valor algum. [...] Mas a situação mudou: órgãos, veias, placentas, tecidos podem ser diversamente reciclados pela indústria, e principalmente hormônios, anticorpos, fragmentos genéticos, linfócitos podem ser isolados, eventualmente multiplicados, fazendo do corpo e de seus restos uma verdadeira matéria-prima (1988, p. 20, apud SANTos, 2011).

Assim, com a biotecnologia, nanotecnologia e manipulação genética, uma nova fronteira de depredação ambiental parece figurar no horizonte.

A engenharia genética, com suas técnicas de seleção, acabará por funcionar como uma máquina de hierarquização social. E, se for socializada, produzirá padronizações. De uma forma ou de outra, todos os cidadãos terão por genitores ou co-genitores a ciência; ou, num caso mais extremo, um Estado totalitário que tutele e determine o perfil biológico de seus cidadãos. Éramos frutos do acaso e das probabilidades, uma espécie de loteria biológica que nos protegia contra a arbitrariedade. A partir de agora, terceiros poderão nos determinar biologicamente. Nós próprios, os únicos direta e essencialmente interessados, só poderemos saber dos resultados quando eles estiverem irreversivelmente impressos em nosso ser pelos códigos genéticos que alguém resolveu escolher sem nossa aprovação (DuPAS, 2006, p. 207).

Nessa perspectiva, após esse panorama situacional da relação economia-meio ambiente, conclui-se que a Amazônia, repositório singular de biodiversidade, configura-se como uma área que merece atenção e cuidados. Observada a partir das correntes ecológicas categorizadas por Joan Martinez Alier, a Amazônia torna-se um alvo-chave para os seguidores do evangelho da ecoeficiência, uma vez que suas potencialidades podem render inúmeras vantagens competitivas, sobretudo econômicas. Considerando o receituário do ecologismo dos pobres, que denuncia a desproporcionalidade dos conflitos distributivos, peixes, árvores, água, minérios e os povos ribeirinhos e indígenas transformam-se em objetos de constante exploração e em matérias-primas disponíveis para a renovação capitalista. A sacralidade da natureza, ideal-base da corrente denominada culto ao silvestre, encontra-se diminuída e desrespeitada, uma vez que se depara com um Estado ora fraco na formulação de políticas socioeconômicas consistentes 
para os povos ribeirinhos e para as regiões de floresta, ora mancomunado com os interesses privados de grandes organizações não governamentais e corporações multinacionais. Encarando as potencialidades da biotecnologia anteriormente mencionadas - que, em muitos casos, poderia ser substituída pelo termo "biopirataria” -, firma-se a necessidade de sérios debates, pois a questão configura-se como uma nova janela de conflitos econômicos, culturais, sociais, ambientais e ético-filosóficos, sobretudo se considerar-se que a biotecnologia representa uma forma assombrosa de depredação ambiental com potencial danoso irreversível e incalculável para o futuro da humanidade.

\section{REFERÊNCIAS BIBLIOGRÁFICAS}

Alencastro, Catarina. Amazônia tem menor índice de desmatamento registrado no mês de agosto. O Globo, Rio de Janeiro, 3 out. 2011. Disponível em: <http://oglobo.globo.com/ pais/mat/2011/10/o3/amazonia-tem-menor-indice-de-desmatamento-registradono-mes-de-agosto-925492224.asp>. Acesso em: 27/10/2011.

Aveline, Carlos Cardoso. A vida secreta da natureza - uma iniciação à ecologia profunda. São Paulo: Editora Bodigaya, 2007.

BRÜZEKE, Franz Josef. O problema do desenvolvimento sustentável como desafio para as ciências. Novos Cadernos Naea, v. 12, p. 141-159, 1994.

CASTRo, E. M. R.. Dinâmica sócio-econocômica e desmatamento na Amazônia. Novos Cadernos Naea, Belém-PA, v. 9, n. 2, p. 5-39, 2005.

DA Silva, Eduardo Augusto. O peso das palavras, o choque dos ideais: uma análise crítica dos Indicadores de Sustentabilidade como critérios para a Gestão da Comunicação Organizacional. 240 p. 2011. Tese (Doutorado em Interfaces Sociais da Comunicação) - Programa de Pós-Graduação em Comunicação da Escola de Comunicações e Artes da Universidade de São Paulo. São Paulo, 2011.

DuPAs, Gilberto. O mito do progresso; ou progresso como ideologia. São Paulo: Editora UNESP, 2006.

GidDEns, Anthony. A política da mudança climática. Rio de Janeiro: Zahar, 2010.

Golçalves, Carlos Walter Porto. Os (des)caminhos do meio ambiente. 14. ed. São Paulo: Contexto, 2006.

Martínez Alier, Joan. O ecologismo dos pobres: conflitos ambientais e linguagens de valoração. São Paulo: Contexto, 2009.

MarTínez Alier, Joan; PorTo, M. F. S. Ecologia política, economia ecológica e saúde coletiva: interfaces para a sustentabilidade do desenvolvimento e para a promoção da saúde. Cadernos de Saúde Pública, Fiocruz, v. 23, p. S503-S512, 2007. 
Porto, Marcelo Firpo; Milanez, Bruno. Eixos de desenvolvimento econômico e geração de conflitos socioambientais no Brasil: desafios para a sustentabilidade e a justiça ambiental. Ciência \& Saúde Coletiva, v. 14, p. 1983-1994, 2009.

Roвغ̀RT, Karl-Henrik. The natural step - A história de uma revolução silenciosa. 11. ed. São Paulo: Editora Pensamento Cultrix, 2011.

Rocha, Maria Eduarda da Mota. A nova retórica do capital: a publicidade brasileira em tempos neoliberais. São Paulo: EdusP, 2010.

SANTOS, Laymert Garcia dos. Desencontro ou "malencontro" - Os biotecnólogos brasileiros em face da sócio e da biodiversidade. Novos Estudos, CEBRAP, v. 78, p. 49-57, 2007. . Politizar as novas tecnologias: o impacto sociotécnico da informação digital e genética. 2. ed. São Paulo: Editora 34, 2011.

SouzA, André Luiz Lopes de. Meio ambiente e desenvolvimento sustentável: uma reflexão crítica. Paper... Núcleo de Altos Estudos Amazônicos (NAEA), UFPA, n. 45, 1995.

Recebido para publicação em 10/05/2013. Aceito para publicação em 19/10/2013. 